\title{
Equity Valuation Using Price Multiples: A Comparative Study for BRICKS
}

\author{
Sanjay Sehgal (Corresponding author) \\ Department of Financial Studies, \\ University of Delhi, South Campus \\ ESC-PAU, France \\ Email: $\underline{\text { sanjayfin15@gmail.com }}$ \\ Asheesh Pandey \\ IILM Institute for Higher Education, \\ Gurgaon \\ Email: asheeshpandey@ rediffmail.com
}

Received: November 30, 2009 Accepted: December 16, 2010

\begin{abstract}
In this paper, we evaluate the efficacy of three value drivers namely, earnings per share, book value and sales for developing stock price forecasts using two performance evaluation criteria: 1) Root Mean Squared Error and 2) Thail Inequality Coefficient. We employ data for BRICKS economies excluding Russia from 1993-2007. We conduct our analysis in three phases. In phase one we find that price to book value is the best standalone price multiple for the Asian economies (India, China and South Korea) while price to earnings does a better job for equity valuation in case of Brazil and South Africa. In the next phase we show that combination of value drivers do not significantly improve price forecast vis-à-vis standalone multiples. Our findings are in contrast with those for developed markets as shown by Penman (1996). We also find that in Indian context market regression is a better tool for price forecasting compared to sector regression as larger number of observations result in better estimator for our forecast equation. Our findings are extremely relevant for equity analysts and portfolio managers who are continuously involved in equity evaluation and developing global asset allocation strategies.
\end{abstract}

Keywords: Price Earnings Ratio, Price to Book Value ratio, Relative Valuation, Price Multiples, Discounted Cash flows

JEL Classifications: C51, C52, G11, G15 


\section{Introduction}

Capital market activity plays an important role in financial system for most of the world economies. The global capital markets have grown manifold both in terms of size as well as operations over the past three decades. The academicians as well as researchers tend to classify these global markets into mature and emerging blocks. The matured markets provide historically low to medium returns and low risk exposures owing to low growth but stable economies with evolved market microstructure and greater institutional trading resulting in mature investor behavior. Emerging markets, on the other hand, are expected to provide high return and risk exposures owing to fast growing but volatile economies involving less evolved market microstructure and greater individual trading leading to less mature investor behavior. BRICKS are large fast growing emerging economies and have caught attention of global portfolios and fund managers who seek to diversify their international portfolios by holding them across different market blocks to take advantage of low correlations.

BRIC (which is a subset of BRICKS) comprises of Brazil, Russia, Indian and China. These economies account for a combined GDP of approximately 15.435 trillion dollars and are estimated to become the most dominant economies by 2050 (see Goldman Sachs, report on Dreaming with BRICs: The path to 2050, (2003)). More recently, the investment banking industry has expanded the emerging markets ${ }^{1}$ basket from BRIC to BRICKS which now additionally includes South Korea and South Africa. BRICKS countries have high potential growth; they cover $30 \%$ of land area of world, $47 \%$ of world population, and have a combined GDP of approximately 17.403 trillion dollars, thus attracting investors from all over the world. Goldman Sachs, have estimated that by 2050 the combined economies of BRICs can become larger than G7 (US, Japan, UK, Germany, France, Canada and Italy) in US dollar terms.

BRICKS countries equity markets have seen a remarkable increase since 2001 in their value: Brazil has risen by $369 \%$, Russia by $630 \%$, India by $499 \%$, China by $201 \%$, South Korea by $460 \%$, and South Africa by $70 \%$ using the A-share market. These countries have economic 
opportunities, as their aggregate contribution to the world output has been $30 \%$ since the year 2000. Their economic growth has greatly influenced and in many cases propelled financial markets. However, there has been a worldwide correction in the past one and a half year in the world capital markets (including emerging markets) owing to current global financial crisis. Given the potential of these emerging economies it is extremely important to study the valuation dynamics in their capital markets.

All assets whether financial or real can be valued, but the complexities and the details of valuation will vary from case to case. The role of valuation is different in different situations. Like in portfolio management the role of valuation is determined by the investment philosophy of the investor. Valuation plays a limited role in portfolio management for a passive investor, whereas it plays a very important role for an active investor. There are different techniques through which analysts value equities. Some analysts use discounted cash flow (DCF) models to value shares, while others use price multiples such as the price earnings and price-book value ratios. Technical analysts believe that prices are driven as much by investor psychology as by any underlying financial variables. Then there are Information traders, who attempt to trade in advance of new information or shortly after it is revealed to financial markets, buying on good news and selling on bad news. Efficient marketers believe that the market price at any point in time represents the best estimate of the true value of the firm, and that any effort to exploit perceived market in-efficiencies will cost more than it will make in extra-normal profits.

While we tend to focus more on discounted cash flow valuation, while discussing valuation, the reality is that most valuations are relative in nature. The value of most assets, from the house one buys to the stocks that one invests in, are based upon how similar assets are priced in the market place. Relative valuation, estimates the value of an asset by looking at the pricing of 'comparable' assets relative to a common variable such as earnings, cash flows, book value or sales. There are two components to relative valuation. The first is that to value assets on a relative basis, prices have to be standardized, usually by converting prices into 
multiples of corporate fundamentals. The second is to find similar firms, which is difficult to do since no two firms are identical and firms in the same business can still differ on risk, growth potential and cash flows. It is the most popular technique of valuing an asset because firstly a valuation based upon a multiple for comparable firms can be quickly estimated with far fewer assumptions and in a speedy manner compared to DCF analysis. Secondly a relative valuation is simpler to understand and easier to present to clients and customers. Finally in situations where market valuations are absent, either because the share capital is privately held, or because the proposed publicly traded entity has not yet been created like in case of spinoffs, relative valuation is the only solution to find value in such cases. Valuations under this approach can be standardized relative to earnings firms generate, to the book value or replacement value of the firms themselves, to the revenues that firms generate or to measure a firm's cash flows. Some of the important multiples in relative valuations are earnings multiples which can be estimated using current earnings per share, yielding a current Price to Earning (P/E), earnings over the last four quarters, resulting in a trailing $\mathrm{P} / \mathrm{E}$, or expected earnings per share in the next year providing a forward $\mathrm{P} / \mathrm{E}$. Book Value (P/BV) or Replacement Value Multiple which is the accounting estimate of book value is determined by accounting rules and is heavily influenced by the original price paid for any assets and any accounting adjustments (such as depreciation, inventory valuation etc.) made since. For those who believe that book value is not a good measure of the true value of assets, an alternative is to use the replacement cost of the assets, the ratio of value of firm to replacement cost is called Tobin's Q. Another important price multiple used in the industry is based on firm revenues which is a ratio of the value of an asset to the revenue it generates. For equity investors this ratio is Price to Sales ratio $(\mathrm{P} / \mathrm{S})$, where the market value per share is divided by the revenues generated per share. Some equity researchers emphasize on Price to Cash flow (P/CF) ratios instead of traditional P/E ratios as the later is impacted by the accounting treatment for certain items, as mentioned for earnings above, in the firm's financial statements.

Analysts rely heavily on relative valuations for forecasting purposes because of their importance as mentioned above. In the investment community, be it Equity Research Firms, 
Venture Capitalists, Trading Firms, Investment Banks, and Hedge Funds etc., relative valuation is the most acceptable technique for valuing stocks apart from DCF valuation. A lot of empirical work has been conducted for matured markets ${ }^{2}$ relating to the robustness of value drivers in deriving equity prices. Similar work for emerging markets including India, is however limited.

The study is organized into 7 sections. Section 2 is devoted to review the related literature. Section 3 describes Data and their sources. Equity valuation using historical price multiples is discussed in section 4. In section 5 we analyze equity valuation using combination of historical price multiples and compare it with our findings for standalone multiples. Section 6 provides a comparison of sector regressions versus market regressions in forecasting prices for the Indian environment. Summary and concluding remarks are contained in the last section.

\section{Review of literature}

There is a lot of literature in textbooks (e.g. Copeland, Koller and Murrin (1994), Damodaran (1996), and Palepu, Healey, and Bernard (2000) discussing price multiples. Interestingly there are a few research papers published on the subject. Among all the value drivers most of the research work has been done on historical earnings and cash flows. Boatsman and Baskin (1981) study the valuation accuracy of P/E multiples based on two sets of comparable firms from the same industry. They observe valuation errors were minimized when comparable firms are chosen based on similar historical earnings growth relative to when they are chosen randomly. Alford (1992) examine the effect of choosing comparables based on industry, size (risk), and earnings growth on the meticulousness of valuation using P/E multiples. He finds that pricing errors decline when the industry definition used to select comparable firms is narrowed from a broad single digit SIC code to classifications based on two and three digits. He also observes that controlling for size and earnings growth over and above industrial controls, does not reduce valuation errors. Kaplan and Ruback (1995) analyze the valuation properties of DCF approach for highly leveraged transactions. They find that though DCF valuations approximate transacted values reasonably well but simple EBITDA 
(earnings before interest, tax, depreciation and Amortization) multiples also result in similar valuation accuracy.

Penman (1996) interprets the P/E ratio \& market to book ratio and describe how they articulate. The study also describes the role of book rate of return on equity (the ratio of their denominators) in the determination of ratios and the relation between them. The study proves that the description of $\mathrm{P} / \mathrm{E}$ ratio reconciles the standard growth interpretation of the $\mathrm{P} / \mathrm{E}$ with the transitory earnings (Molodovsky effect, 1953) interpretation. Both are correct only in special cases. Penmen (1997) investigate approximate benchmark valuations that combine earnings $\&$ book value together. He estimate weights such that a benchmark price $=$ w $1 *$ book value $+\mathrm{w} 2 *$ earnings is calculated and he also examines the robustness of these weights over time. The study shows that weights vary in a nonlinear way over the amount of earnings relative to book value, and systematically so over time. It also demonstrates that estimated weights are robust over time and can be used to predict prices when applied out of sample. Tasker [1998] compares across-industry patterns in the selection of comparable firms by investment bankers and analysts in acquisition transactions. She finds the systematic use of industry-specific multiples, which is consistent with different multiples being more appropriate in different industries Beatty, Riffe, and Thompson [1999] analyze different linear combinations of value drivers derived from earnings, book value, dividends, and total assets. They derive and document the benefits of using the harmonic mean, and introduce the price-scaled regressions. They find the best performance is achieved by using (1) weights derived from harmonic mean book and earnings multiples and (2) coefficients from price-scaled regressions on earnings and book value.

Baker and Ruback [1999] empirically show that industry multiples estimated using the harmonic mean are close to minimum-variance estimates based on Monte Carlo simulations. They use the harmonic mean estimator to calculate multiples based on EBITDA, EBIT, and sales, and find that industry-adjusted EBITDA performs better than EBIT and sales.

Instead of focusing only on historical accounting numbers, Kim and Ritter [1999], in their 
investigation of how initial public offering prices are set using multiples, add forecasted earnings to a conventional list of value drivers, which includes book value, earnings, cash flows, and sales. They find that forward P/E multiples, based on forecasted earnings, dominate all other multiples in valuation accuracy, and that the Earning Per Share (EPS) forecast for next year dominates the current year EPS forecast.

Liu, Nissim, \& Thomas (March 2002) examine the valuation performance of a comprehensive list of value drivers to find out which of them best explains the stock prices. They find in terms of relative performance forward earnings measures are followed by historical earnings measures, cash flow measures and book value of equity are tied for third, and sales performs the worst. Liu, Nissim \& Thomas (September 2002) extend their previous work for 10 different countries. However, all the companies belong to the matured markets. They find out that multiples based on earnings perform the best, those based on sales perform the worst \& dividends and cash flow multiple exhibit intermediate performance. Second, using forecasts improve performance over multiples based on reported numbers with greatest (smallest) improvement being earnings (sales). Liu, Nissim \& Thomas (2007) try to find out whether valuations based on cash flow multiples are better than earnings multiple. They observe that despite intuitive claims that operating cash flows are better than earnings as a summary measure of value, stock prices are better explained by reported earnings than reported operating cash flows.

Huang, Tsai and Chen (2007) re - examine the P/E anomaly by decomposing P/E ratios into a fundamental component and a residual component, which enables them to capture factors that potentially provide better measures of investor overreaction. They find that both firm specific and macroeconomic factors determine P/E multiples. Da and Schaumburg (2008) document that within industry relative valuations implicit in analyst target prices do provide investors with valuable information although the implied absolute valuations themselves are much less informative. 
Small body of literature on price multiples is also available for emerging markets including India. Irina, Alexander and Ivan (2007) prove that using peers from developed markets would overstate the estimation of equity value in emerging market, because companies from emerging markets are subject to various factors such as political and economic risks, low level of corporate governance and high negative skewness etc., and thus require an adequate discount rate by applying an adjustment factor in emerging markets. Gill (2003) demonstrates empirically that the stock market valuations are no longer driven solely by traditional investment principles. She find that the low P/E ratio as an indicator does not hold good anymore and there is nothing like a long-term investment strategy. Dhankar \& Kumar (2007) measure the performance of a set of portfolios, which are based on P/E of stocks. The study finds no consistency between the portfolios' expected return and their corresponding $\mathrm{P} / \mathrm{E}$ ratios. It observes that the stock market failed to reflect instantaneous response pertaining to earnings information. Their findings question the efficient market hypothesis but hold the application of capital asset pricing model in the Indian stock market.

Sehgal and Pandey (2009a) examine the behavior of price multiples in India from 1990-07. They observe that price multiple distributions tend to be normal over the study period, thus, making mean and standard deviation of these multiples as relevant parameters for equity analysis in the Indian context. They also find that there is a very weak relationship between price multiples and their fundamental determinants and hence the cross-sectional linear models do not seem to be good descriptors of price multiples. The study also proves that price multiples also seem to be sensitive to market conditions and therefore are generally higher in upturns with the exception of infrastructure related sectors. Sehgal and Pandey (2009b) evaluate alternative price multiples for equity valuation purposes in the Indian context. They find that price to Earnings provide the best price forecast compared to other three price multiples i.e. price to book value, price to cashflow and price to sales. The study also reveals that historical price to earnings as a standalone multiple does a better job in equity valuation vis a vis all value driver combinations.

Thus, there seems to be a major research gap on the subject for emerging markets. Most of 
the work done in emerging markets relates to $\mathrm{P} / \mathrm{E}$ ratios while no concrete research has been done on other value drivers like book value, sales $\&$ cash flows. In this paper, we attempt to test the efficacy of alternative price multiples for BRICKS, which are the most important set of countries in emerging market basket.

The study has the following objectives: (1) To understand which standalone value driver is best for forecasting prices, (2) To evaluate whether combination of value drivers forecast prices better than standalone value drivers. Its corollary would be that if a combination of value drivers gives superior results than standalone value drivers then it means different value drivers provide separate pieces of information for valuing stock, and hence they should be combined to get the fair price and (3) To estimate whether price forecasting is better when one uses sector regressions instead of market regressions. We verify the last objective only for the Indian market owing to lack of sectoral information for other BRICK countries.

\section{Data}

We use data for six emerging economies, namely Brazil, Russia, India, China, South Korea and South Africa (known as BRICKS) in our study. The data source is Thomson Reuters Datastream Software ${ }^{5}$. The sample financial ratios have been taken from Thomson Reutors Datastream software which provides standardized data for all markets (as per global accounting practices). Hence, differences in accounting system across countries do not pose problems for cross country comparisons. The sample period is 1993-2007 (15 years). For each country sample companies are selected based on the following criteria: (1) 250 large cap companies for each country are selected on the basis of year end market capitalization for the last sample year (2007). In case of Brazil and South Africa, since the data was available only for 195 and 253 companies respectively, hence we use the entire basket without applying the market capitalization rule, (2) the shortlisted companies must have prices available for at least 7 years out of the total sample period, (3) All the companies with prices of less than Rs. 20 in a particular year have been omitted out of the sample for that year. This has been done to remove the effect of penny stocks in forecasting the prices as they can make large distortions in forecasted prices and, (4) the value drivers per share should be positive for a company in a 


\section{Al Macrothink}

Asain Journal of Finance \& Accounting

ISSN 1946-052X

2010, Vol. 2, No. 1: E4

given year. The details of sample companies for BRICKS are given in Exhibit A. We omit Russia from our study owing to negligible number of companies which satisfy our filtering criteria. The data set comprises of three value drivers namely EPS, BV and Sales for each sample company. We exclude cashflow as a value driver from our work owing to lack of relevant data for all sample companies except India. The definitions for value drivers are given in Exhibit B. All information related to stock prices and value drivers (EPS, BV and Sales) have been taken for the end of March for each sample year. This is required to compare results for India with other BRICKS countries. It may be noted Financial Year is April of year $\mathrm{t}$ to March of year $\mathrm{t}+1$ for India. In the Indian context we additionally compare the price forecasts provided by sector regressions as well as market regressions. For sector regressions we use data for 13 out of 20 major sectors based on sector classification of Bombay Stock Exchange 500 index (BSE500) ${ }^{4}$. Two sectors namely, Diversified and Miscellaneous are excluded from our work as they are difficult to benchmark while other five sectors (i.e. Media and Publishing, Tourism, Telecom, Consumer Durable and Transport Services) have been omitted as they have few listed companies with not so frequent trading record. For each sector 5 - 12 large cap ${ }^{5}$ companies are selected based on the criteria mentioned above. The data details for sample sectors for India are given in Exhibit C.

\section{Exhibit A: Details of Sample Companies for BRICKS}

\begin{tabular}{lll}
\hline Country & $\begin{array}{l}\text { No. of Companies } \\
\text { before Screening }\end{array}$ & $\begin{array}{l}\text { No. of Companies } \\
\text { after Screening }\end{array}$ \\
\hline Brazil & 195 & 195 \\
\hline Russia & 75 & - \\
\hline India & 500 & 145 \\
\hline China & 1492 & 200 \\
\hline South Korea & 931 & 200 \\
\hline South Africa & 253 & 253 \\
\hline
\end{tabular}


Exhibit B: Definitions of Price and Value Drivers

\section{Definitions}

Price Closing Price

\begin{tabular}{ll}
\hline EPS & $\begin{array}{l}(\text { Net Profit }- \text { Preference Dividend - } \\
\left.\text { Dividend } \operatorname{Tax}^{6}\right) / \text { Number of Shares }\end{array}$ \\
\hline Book Value & Net worth / Number Of Shares \\
& $\begin{array}{l}\text { And Net worth= Equity }+ \text { Reserves \& } \\
\text { Surplus }\end{array}$ \\
\hline Sales & Net Sales = Gross Sales - Excise Duty \\
\hline
\end{tabular}

Exhibit C: Details of Sample Sectors for India

\begin{tabular}{lll}
\hline Serial No. & Sector & No. of Companies \\
\hline 1 & Agriculture & 12 \\
\hline 2 & Capital Goods & 12 \\
\hline 3 & Chemical \& Petrochemical & 12 \\
\hline 4 & Finance & 12 \\
\hline 5 & Fast Moving Consumer Goods (FMCG) & 12 \\
\hline 6 & Healthcare & 12 \\
\hline 7 & Housing Related & 12 \\
\hline 8 & Information Technology (IT) & 12 \\
\hline 10 & Metal, Metal Products \& mining & 12 \\
\hline 11 & Oil \& Gas & 12 \\
\hline 12 & Power & 6 \\
\hline 13 & Textile & 7 \\
\hline
\end{tabular}

\section{Equity valuation using historical price multiples}

In this section we evaluate standalone price multiples to find out which one of them is most efficient in forecasting prices for BRICKS. We forecast historical prices using three standalone value drives namely, EPS, BV, and Sales. Forecasted price for each year is calculated by using market regression procedure which has been explained below. We then subtract forecasted price from the actual price each year to get the series of pricing errors for the sample period. We next calculate Root Mean Squared Error (Root MSE) and Thail 
Inequality Coefficient for the series of pricing errors obtained for the sample companies. The price multiple for which pricing errors are minimum will be termed as the most efficient one for valuing a share using historical data.

In order to compute the forecasted price OLS estimation can be done including an intercept term as shown in the following equation:

$p_{i t}=\alpha_{t}+\beta_{t} \cdot \chi_{i t}+\varepsilon_{i t}$

where, $\alpha_{t}$ is the intercept which captures the average effect of those factors which are not explained by value driver, $x_{i t}$ is the value driver for firm i in year $t, \beta_{t}$ is the multiple on the value driver and $\mathrm{e}_{\mathrm{it}}$ is the pricing error.

Many factors besides the value driver under investigation, affect price, and the average effect of such omitted factors is unlikely to be zero. Since the intercept in equation (1) captures the average effect of omitted factors, allowing for an intercept should improve the precision of out of sample predictions.

Through above equation we regress the base year price on the base year's value driver and use the OLS estimates to find out expected price ${ }^{7}$ for base year.

To improve the estimation efficiency, we divide equation (1) by expected price.

$\frac{p_{i t}}{\hat{p_{i t}}}=\frac{\alpha_{t}}{\hat{p_{i t}}}+\beta t \frac{\chi_{i t}}{\hat{p_{i t}}}+\frac{\varepsilon_{i t}}{\hat{p_{i t}}}$

We divide equation (1) by expected Price and make it a GLS estimation equation in order to remove the effect of heteroscedasticity and to obtain a more efficient estimate of value driver. $\operatorname{Var}\left(\varepsilon_{\mathrm{i}}\right)$ is hetroscadic with respect to square of expected prices in the form of $\operatorname{Var}\left(\varepsilon_{\mathrm{i}}\right)=\mathrm{f}(\mathrm{E}$ $\left.\left(\mathrm{P}_{\mathrm{i}}\right)^{2}\right)$. Step 2 is performed only in those cases where there is significant heteroscedasticity as shown by white hetroskedasticity (no cross term term) residual test ${ }^{8}$. 


\section{Macrothink}

Estimating equation (2) with no restriction minimizes the square of pricing errors, but the expected value of these errors is non zero. Empirically it has been proved by Liu, Nissim, and Thomas (2002) that when we impose the restriction that expected pricing errors $(E(\varepsilon / p))$ be zero it generates lower pricing errors for most firms, relative to an unrestricted estimate, but it generates substantially higher errors in the tail of the distribution. By restricting ourselves to unbiased pricing errors, we are in effect assigning lower weights to extreme pricing errors, relative to unrestricted approach. By doing so we are also maintaining consistency with the tradition in econometrics that strongly prefers unbiasedness over reduced dispersion. Therefore, we impose the restriction that pricing errors be unbiased. That is, we seek to estimate the Parameters $\quad \alpha_{\mathrm{t}}$ and $\beta_{\mathrm{t}}$ that minimize the variance of $\left(\frac{\boldsymbol{\varepsilon}_{i t}}{\hat{p_{i t}}}\right)$,

subject to the restriction that expected value of residual term is zero:

$$
\begin{aligned}
& \min _{\alpha, \beta} \operatorname{var}\left(\frac{\mathcal{E}_{i t}}{\hat{p_{i t}}}\right)=\operatorname{var}\left[\frac{\hat{p_{i t}}-\alpha_{t}-\beta_{t} \cdot \chi_{i t}}{\hat{p_{i t}}}\right]=\operatorname{var}\left(1-\left[\alpha_{t} \frac{1}{\hat{p_{i t}}}+\beta_{t} \frac{\chi_{i t}}{\hat{p}_{i t}}\right]\right) \\
& \text { s.t. } \quad \mathrm{E}\left(\frac{\mathcal{E}_{i t}}{\hat{p_{i t}}}\right)=0
\end{aligned}
$$

It can be shown that the estimates for $\alpha_{t}$ and $\beta_{t}$ that satisfy (3a) and (3b) are as follows:

$$
\mathrm{B} t=\frac{\mathrm{E}\left(\frac{\chi_{t}}{\hat{p}_{i t}}\right) \operatorname{var}\left(\frac{1}{\hat{p_{i t}}}\right)-\operatorname{cov}\left(\frac{1}{\hat{p_{i t}}}, \frac{\chi_{t}}{\hat{p_{i t}}}\right) E\left(\frac{1}{\hat{p}_{i t}}\right)}{\mathrm{E}\left(\frac{1}{\hat{p}_{i t}}\right)^{2} \operatorname{var}\left(\frac{\chi_{t}}{\hat{p_{i t}}}\right)+\mathrm{E}\left(\frac{\chi_{t}}{\hat{p}_{i t}}\right)^{2} \operatorname{var}\left(\frac{1}{\hat{p_{i t}}}\right)-2 \mathrm{E}\left(\frac{1}{\hat{p_{i t}}}\right) \mathrm{E}\left(\frac{\chi_{t}}{\hat{p}_{i t}}\right) \operatorname{cov}\left(\frac{1}{\hat{p_{i t}}}, \frac{\chi_{t}}{\hat{p}_{i t}}\right)}
$$




$$
\alpha_{t}=\frac{1-\beta_{t} E\left(\frac{\chi_{t}}{\hat{p_{i t}}}\right)}{E\left(\frac{1}{\hat{p_{i t}}}\right)}
$$

where, the different Et[.], var(.), and $\operatorname{cov}($.$) represent the means, variances, and covariances of$ those expressions for the population, and are estimated using the corresponding sample moments for the comparable group.

After putting the above said restriction we compute the forecasted price for next year through GLS estimation.

We next estimate pricing errors, defined by equation (6), and examine their distributions to determine performance.

$$
\frac{\varepsilon_{i t}}{\hat{p_{i t}}}=\frac{p_{i t}-\hat{\alpha}_{t}-\hat{\beta}_{t} \chi_{i t}}{\hat{p_{i t}}}
$$

The pricing error is calculated as a difference between actual and forecasted price. We repeat the same procedure for each country for all the sample years.

We compute Root MSE and Thail Inequality Coefficient on the series of pricing errors over the study period and the price multiple with minimized pricing error is termed as the most efficient one.

Root Mean Squared Error depends on the scale of dependent variable. It is used as a relative measure to compare forecasts for the same series across different models. According to this criterion the smaller the error in a model, the better is the forecasting ability of that model. It is calculated as follows: 
Root Mean Squared Error $=\sqrt{\frac{\sum_{t=t+1}^{T+h}\left(y_{t}-\hat{y}_{t}\right)^{2}}{h}}$

Where,

$y_{t}=$ Observed value

$\hat{y}_{t}=$ forecasted value

$\mathrm{h}=$ number of observations

Thail Inequality Coefficient is scale invariant. It always lies in between 0 and 1, where 0 indicates a perfect fit. It is estimated as follow:

Thail Inequality Coefficient $=\frac{\sqrt{\frac{\sum_{t=t+1}^{T+h}\left(y_{t}-\hat{y}_{t}\right)^{2}}{h}}}{\sqrt{\frac{\sum_{t=T+1}^{T+h} y_{t}^{2}}{h}+\sqrt{\frac{\sum_{t=T+1}^{T+h} \hat{y}_{t}^{2}}{h}}}}$

Through these two measures we evaluate the market pricing errors to determine the most efficient price multiple based on error minimization criteria. The price multiple whose pricing error, as per both measures, is least among the three multiples viz. $\mathrm{P} / \mathrm{E}, \mathrm{P} / \mathrm{BV}$ and $\mathrm{P} / \mathrm{S}$ will be termed as the most efficient one in forecasting prices.

We find that the pricing errors for forecasted prices based on P/BV multiples are lowest for India, China and South Korea as compare to other multiples, using both the forecast evaluation measures. As shown in Table1 P/BV exhibits minimum pricing error for these three Asian economies. $\mathrm{P} / \mathrm{E}$ is the next efficient price multiple whereas $\mathrm{P} / \mathrm{S}$ is the worst performer according to both the tests. We also observe that in case of India and China errors given by Book Value and EPS are almost equal, wherein BV has a slight edge over EPS. On the other hand for the two non Asian economies i.e. Brazil and South Africa, P/E proves to be the better multiple for forecasting prices as per both the criteria. Hence, we can conclude that 
in case of emerging economies price forecasting should be done by $\mathrm{P} / \mathrm{E}$ or $\mathrm{P} / \mathrm{BV}$ ratios.

\section{Equity valuation using combined historical multiples}

In this section we evaluate combined historical price multiples to verify the following propositions:

i. Which is the best combination for forecasting prices and

ii. How do the combined multiples perform vis-à-vis standalone multiples in equity valuation.

We evaluate three combinations of value drivers' namely: EPS-BV, EPS-Sales, and BV-Sales to analyze combined historical multiples. We follow the following estimation process:

In step 1 we make stock price as a function of a combination of value drivers as shown in equation (9) below.

$p_{i t}=\alpha_{t}+\beta_{1 t} \cdot \chi_{1 t}+\beta_{2 t} \cdot \chi_{2 t}+\varepsilon_{i t}$

where, $\alpha_{t}$ is the intercept which captures the average effect of those factors which are not explained by value driver, $\mathrm{x}_{\text {it }}$ is the value driver for firm $\mathrm{i}$ in year $\mathrm{t}, \beta_{1 t}$ and $\beta_{2 t}$ are price multiples for the respective value drivers and $\mathrm{e}_{\mathrm{it}}$ is the pricing error.

Through above equation we regress the base year price with the base year's value drivers to find out expected price for base year.

To improve the estimation efficiency, we divide equation (9) by expected price. This Step is performed only in those cases where there is significant heteroscedasticity as shown by white hetroskedasticity (no cross term) residual test.

$\frac{p_{i t}}{\hat{p_{i t}}}=\frac{\alpha_{t}}{\hat{p_{i t}}}+\beta_{1 t} \frac{\chi_{1 t}}{\hat{p_{i t}}}+\beta_{2 t} \frac{\chi_{2 t}}{\hat{p_{i t}}}+\frac{\varepsilon_{i t}}{\hat{p_{i t}}}$ 
We estimate equation (10) imposing the restriction for the error term specified in the previous section i.e, $\quad\left(\frac{\boldsymbol{E}_{i t}}{\hat{p}_{i t}}\right)=0 \quad$ so that our regression estimates are unbiased. We obtain forecasted prices from equation (10) and then use them to calculate our pricing errors using equation (8).

We adopt Root MSE and Thail Inequality Coefficient as our criteria for checking the quality of price forecast as was done in previous section.

The results for combined multiples are given in Table 2. While analyzing pricing error distributions for combined multiples we find that for India and China the errors are minimum for the combination of BV-Sales value drivers according to both the criteria. EPS-Sales is the next best value driver while EPS-BV performs worst in forecasting prices. However, it is to be noted that pricing errors through EPS-Sales are almost equal to BV-Sales for India and China. In case of other three emerging economies EPS-BV is a better measure than other two combinations of value drivers as per both the criteria.

We next compare standalone value drivers with value driver combinations. It can be seen from Tables 1 and 2, that BV (the best standalone value driver) outperforms BV-Sales (the best combination of value drivers) for India as per both the evaluation criteria. The value driver combinations do not consistently do better than standalone value drivers as per our evaluation criteria for China and South Korea.

On the other hand for Brazil and South Africa we get inconsistent results as per both the criteria. In case of South Africa, EPS (the best standalone value driver) performs better than EPS-BV (the best combination of value driver) while for Brazil EPS-BV gets better results than EPS as per Root Mean Squared Error. While as per Thail Inequality Coefficient criteria EPS and EPS-BV are the best multiples in forecasting prices for Brazil and South Africa respectively. We conclude that in general combining value drivers does not improve our price 
forecast and hence, equity valuations can be better done by keeping the process simple by using standalone multiples. Our results for emerging markets are in contrast with Penman (1997), who finds that combined value drivers do a better job than standalone value drivers in case of matured markets. Our findings may be explained by the fact that different price multiples are driven more by investor sentiment in emerging markets where the investors do not perceive each price multiple to be providing different information. See Sehgal and Pandey (2009). Hence, use of multivariate models does not improve our price forecasts.

\section{Sector regressions versus Market regressions: The Indian Case}

In this section we analyze Indian companies to find out whether sector regressions better explain the stock prices than market regressions. Sector regressions are not performed for other sample countries as sector classification information for them is not available with us. In case of sector regressions the price forecasts are obtained using data for sample companies belonging to a particular sector. We calculate pricing errors by taking the difference between actual and forecasted prices. The distributions of pricing errors are then used to estimate our forecast evaluation criteria namely, Root MSE and Thail Inequality Coefficient. In case of market regressions, the estimation procedure is similar except that price forecasts are obtained by using information for all the sample companies i.e. for the market as a whole. Some equity analysts argue that sector regressions are better than market regressions owing to the fact that the former controls for inter - sectoral differences while developing price forecast. Others argue in favour of market regressions as all securities compete with each other for each dollar of investment in financial markets, irrespective of their sector classification. The data employed for India is same as is used in section 3.

We find that pricing errors are lower for market regressions compared to sector regressions as is shown in Table 3 both for standalone as well as for pairwise combination of value drivers as per both the evaluation criteria. The reason for this could be that in market regressions the number of sample companies for each sample year is far greater than the number of sample 
companies used for sector regressions. The high degree of freedom in case of market regressions may result in better parameter estimation for price forecast purposes. Our results show that contrary to popular belief that price multiples based on sector regressions result in better forecasting of prices, we find that market regressions provide better performance. We therefore, suggest that market regressions should be preferred over sector regressions for equity valuation in the Indian context. We could not do similar analysis for other BRICKS countries owing to lack of sector classification information for them. Similar work for these countries shall be greatly useful for equity analysts and global portfolio managers.

\section{Summary and concluding remarks}

In this study we evaluate the efficacy of alternative value drivers namely, EPS, BV and Sales in providing price forecasts. We conduct this analysis for BRICKS (excluding Russia) which is the most important basket amongst the emerging markets. We employ two performance evaluation criteria i.e. Root MSE and Thail Inequality Coefficient for checking the accuracy of our price forecasts.

Our work involves three phases. In phase one we evaluate the price forecasts provided by standalone price multiples and find that while BV is the best value driver in case of Asian economies (India, China and South Korea), EPS performs best for Brazil and South Africa. In the second phase we experiment with binary combinations of value drivers and find that BV-Sales is the best combination for India and China, while BV-EPS provides best price forecasts for Brazil, South Korea and South Africa. We further observe that combinations of value drivers do not seem to outperform standalone multiples. We recommend that equity valuation process for the sample countries should be kept simple by using relevant standalone price multiples as use of additional multiples do not seem to be providing any significant extra information to investors for developing price forecast. Our findings on emerging markets are in contrast with those for matured markets as shown by Penman (1997). 
In the final phase we verify if sector regressions result in lower pricing errors compared to market regressions in the Indian context. We could not conduct similar analysis for other countries owing to lack of sectoral information. We find that contrary to popular belief sector regressions perform worse than market regressions. While estimating price forecasts our results may be outcome of the fact that market regressions are estimated using large pool of observations (sample companies) resulting in more efficient estimation of the parameters involved in our forecast regressions. We suggest that market regressions should be preferred over sector regressions for equity valuation in the Indian environment. Similar companies for other BRICKS countries are desirable and should be covered in further research.

Our findings are extremely relevant for equity analysts and global portfolio managers who are continuously involved in security evaluation and developing strategic allocation strategies involving distribution of investible funds across world markets including BRICKS. Our study contributes to the equity valuation literature for emerging markets. Similar work for other world markets is desirable for inter-country comparisons on the subject.

\section{$\underline{\text { Notes }}$}

1. Emerging Markets: For details refer to Irina, Alexander and Evan (2007), Gill (2003), Dhankar and Kumar (2007), and Sehgal and Pandey (2009).

2. Matured Markets: For details refer to Boatsman and Baskin (1981), Alford (1992), Kaplan and Ruback (1995), Penman (1996), Penman (1997), Tasker (1998), Baker and Ruback (1999), Beatty, Riffe and Thompson (1999), Kim and Ritter (1999), Liu, Nissim and Thomas (2002), Liu, Nissim and Thomas (2007), Huang, tsai and Cheng (2007)and Da and Schaumburg (2008).

3. Thomson Reuters - Datastream Software: It is a financial and macroeconomic database, covering major instruments, company fundamentals, equities, fixed income securities and economic indicators for 177 countries and 60 markets worldwide.

4. BSE 500: Bombay Stock Exchange Limited constructed a new index, christened BSE-500, consisting of 500 scrips w.e.f. August 9, 1999. BSE-500 index represents nearly $93 \%$ of the total market capitalization on BSE. BSE-500 covers all 20 major industries of the economy. In line with other BSE indices, effective August 16, 2005 calculation methodology was shifted to the free-float methodology. 


\section{Ml Macrothink}

5. Large Cap: In Indian context large cap is a term used by the investment community to refer to companies with a market capitalization value of more than $\$ 5$

billion. Large cap is an abbreviation of the term "large market capitalization". Market capitalization is calculated by multiplying the number of a company's shares outstanding by its stock price per share.

6. Dividend Tax: It is an additional tax to be paid by domestic companies when they declare and distribute dividend among equity shareholders. The tax is levied at prescribed rate (for example in India it is $15 \%+7.5 \%+3 \%$ (dividend tax + surcharge + SHEC) on the amount which is meant for the payment of dividend).

7. Expected price is computed by using the parameters estimated in equation (1) in the

$$
\text { form } \hat{p}_{i t}=\alpha+\beta \cdot \chi_{i t}
$$

Where, $\chi_{i t}=$ value driver

8. White Hetroskedasticity Test: These tests are the extension of White's (1980) test to systems of equations as discussed by Kelejian (1982) and Doornik (1995). The test regression is run by regressing each cross product of the residuals on the cross products of the regressors and testing the joint significance of the regression. The No Cross Terms option uses only the levels and squares of the original regressors, while the With Cross Terms option includes all non- redundant cross-products of the original regressors in the test equation. The test regression always includes a constant term as a regressor. If the chi-square value at the chosen level of significance, or if the p-value of the compute chi square value is reasonably low (say $1 \%$ or $5 \%$ ), we can reject the null hypothesis of hetrocedasticity.

\section{References}

Alford, A. (1992).The effect of the set of comparable firms on the accuracy of the price-earnings valuation method. Journal of Accounting Research, 30, 94-108

Anthony, E. Bopp. (1985). On Combining Forecasts: Some Extensions And Results. Management Science, 31, 1492-1498

Baker, M., \& Ruback, R. (1999). Estimating Industry Multiples. working paper: Harvard University, Cambridge, MA

Beatty, R.P., Riffe, S.M., \& Thompson, R. (1999).The method of comparables and tax court valuations of private firms: an empirical investigation. Accounting Horizons, $13,177-199$

Boatsman, J., \& Bakin, E. (1981). Asset valuation with incomplete markets. The 
Accounting Review, 56, 38-53.

Copeland, T., Koller, T., \& Murrin. J. (1994). Valuation . New York: Willey

Da, Z., \& Schaumburg, E. (2011). Relative Valuation and Analyst Target Price Forecasts. Journal of Financial Markets, 14, 161-192

Damodaran, A. (1996). Damodaran on Valuation. New York: Willey Huang, Y., Tsai, C.H., \& Chen, C.R. (2007). Expected P/E, Residual P/E, and Stock Return Reversal: Time - Varying Fundamentals or Investor Overreaction?. International Journal of Business and Economics, Vol. 6, No.1, 11-28

Irina, I., Alexander, P., \& Ivan, K. (2007). Adjustments to Market Multiples - Based Valuation in Emerging Markets: Empirical Study for Russia. Working paper, Corporate Finance Center, Higher School of Economics, Moscow, Russia

Kaplan, S. N., \& Ruback, R. S. (1995). The valuation of cash flow forecasts: An empirical analysis. The Journal of Finance, 50, 1059-1093

Kim, M., \& Ritter,J. (1999). Valuing IPOs. Journal of Financial Economics, 53, 409-37. Koutroumanidis, T., Iliadis, L., \& Sylaois, G.K. (1986).The Fisher Hypothesis Under Different Monetary Regime. The Review of Economics and Statistics, 68, 674-679

Liu, J., Nssim, D., \& Thomas, J. (2002a).Equity Valuation Using Multiples. Journal of Accounting Research, 40, 135-172

Liu, J., Nissim, D., \& Thomas, J. (2002b). International Equity Valuation using multiples. Working Paper, Anderson Graduate School of Management, University of California at Los Angeles.

Liu, J., Nissim, D., \& Thomas, J. (2007). Is Cash Flow King in Valuations. Financial Analyst Journal, Volume 63, 56-65.

Palepu, K., Healey, P., \& Bernard, V. (2000).Business Analysis and Valuation (2nd ed). Cincinnati, Ohio: South Western College Publishing

Penman, S. H. (1996a). The Articulation of Price-Earnings Ratios and Market -toBook Ratios and the Evolution of growth. Journal of Accounting Research, 34, 253-259

Penman, S. H. (1997). Combining Earnings and Book Value in Equity Valuation. Working Paper, Columbia University, Department of Accounting 


\section{Macrothink}

Sehgal, S. \& Pandey, A. (2009). The Behavior of Price Multiples in India (1990-2007). Asian Academy of Management Journal of Accounting and Finance, 5, 31-65

Sehgal, S. \& Pandey, A. (2010). Equity Valuation using Price Multiples: Evidence from India. Asian Academy of Management Journal of Accounting and Finance, 6, 89-108

Tasker, S. C. (1998). Industry preferred multiples in acquisition valuation. Working paper, Cornell University, Ithaca, NY

Thomas,A.Barthold., \& William.R, Dougan. (1986). The Fisher Hypothesis Under Different Monetary Regimes. The Review of Economics and Statistics, 68, 674-679

Tables

\begin{tabular}{|c|c|c|c|}
\hline \multicolumn{4}{|c|}{ Panel A: Root Mean Squared Error } \\
\hline & EPS & BV & Sales \\
\hline India & 245.371 & 227.190 & 266.736 \\
\hline China & 83.427 & 82.111 & 87.087 \\
\hline Brazil & 740.142 & 1137.737 & 1307.666 \\
\hline South Korea & 18196.243 & 7635.384 & 27903.628 \\
\hline South Africa & 220.254 & 304.812 & 303.202 \\
\hline \multicolumn{4}{|c|}{ Panel B: Thail Inequality Coefficient } \\
\hline & EPS & BV & Sales \\
\hline India & 0.392 & 0.387 & 0.434 \\
\hline China & 0.526 & 0.527 & 0.538 \\
\hline Brazil & 0.287 & 0.427 & 0.429 \\
\hline South Korea & 0.763 & 0.325 & 0.656 \\
\hline South Africa & 0.288 & 0.348 & 0.398 \\
\hline
\end{tabular}




\begin{tabular}{|l|r|r|r|}
\hline $\begin{array}{l}\text { Table 2: Pairwise Combination of Value } \\
\text { Drivers }\end{array}$ \\
\hline \multicolumn{5}{|l|}{ Panel A: Root Mean Squared Error } \\
\hline & EPS-BV & \multicolumn{1}{l|}{ EPS-Sales } & \multicolumn{1}{l|}{ BV-Sales } \\
\hline India & 1672.848 & 257.125 & 255.150 \\
\hline China & 126.842 & 83.142 & 82.239 \\
\hline Brazil & 325.810 & 643227.393 & 1090.400 \\
\hline South Korea & 4268.134 & 9748.881 & 12061.061 \\
\hline South Africa & 229.338 & 308.101 & 684.993 \\
\hline \hline & & & \\
\hline & Eanel B: Thail Inequality Coefficient \\
\hline \multicolumn{5}{|r|r|}{ EPV } & EPS-Sales & BV-Sales \\
\hline India & 0.825 & 0.389 & 0.395 \\
\hline China & 0.662 & 0.527 & 0.526 \\
\hline Brazil & 0.235 & 0.998 & 0.423 \\
\hline South Korea & 0.339 & 0.575 & 0.530 \\
\hline South Africa & 0.276 & 0.359 & 0.569 \\
\hline
\end{tabular}

\begin{tabular}{|l|r|l|l|l|}
\hline Table 3: Sector Vs Market Regressions for India \\
\hline & \multicolumn{2}{|c|}{ Root Mean Squared Error } & \multicolumn{2}{l|}{ Thail Inequality Coefficient } \\
\hline & $\begin{array}{l}\text { Sector } \\
\text { Regression }\end{array}$ & $\begin{array}{l}\text { Market } \\
\text { Regression }\end{array}$ & \multicolumn{1}{l}{$\begin{array}{l}\text { Sector } \\
\text { Regression }\end{array}$} & $\begin{array}{l}\text { Market } \\
\text { Regression }\end{array}$ \\
\hline EPS & 290.91 & 245.371 & 0.418 & 0.392 \\
\hline BV & 322.321 & 227.190 & 0.456 & 0.387 \\
\hline Sales & 678.838 & 266.736 & 0.648 & 0.434 \\
\hline EPS-BV & 9166.62 & 1672.848 & 0.960 & 0.825 \\
\hline EPS-Sales & 560.851 & 257.125 & 0.576 & 0.389 \\
\hline BV-Sales & 332.357 & 255.150 & 0.440 & 0.395 \\
\hline
\end{tabular}

\section{Copyright Disclaimer}

Copyright reserved by the author(s).

This article is an open-access article distributed under the terms and conditions of the Creative Commons Attribution license (http://creativecommons.org/licenses/by/3.0/). 